\title{
Dendritic nonlinearities enable PFC microcircuits to serve as predictive modules of persistent activity
}

\author{
Athanasia Papoutsi ${ }^{1,2^{*}}$, Panagiotis C Petrantonakis ${ }^{1}$, Panayiota Poirazi ${ }^{1}$ \\ From Twenty Second Annual Computational Neuroscience Meeting: CNS*2013 \\ Paris, France. 13-18 July 2013
}

The ability to monitor and probe the activity of large neuronal networks both in vivo and in vitro has recently established that neurons of various brain regions are organized into spatially restricted clusters (or small assemblies) that are bi-directionally connected, share common inputs and are co-activated during behavioral tasks $[1,2]$. Investigations regarding the functional implications of such neuronal clustering have proposed that this modularity may underlie the spiking irregularities seen in cortical activity in vivo [3] or code for the execution of a voluntary movement [4]. In the prefrontal cortex (PFC), such microcircuits are proposed to support the spontaneous emergence of Up and Down states [5], a phenomenon linked to persistent activity, which is the cellular correlate of working memory.

In this work we investigate the functional role of PFC microcircuits in the expression of persistent activity, focusing on the contribution of nonlinear dendritic properties to the induction, termination, and coding of upcoming state transitions.

Towards this goal we developed a layer V PFC microcircuit consisting of 7 pyramidal neurons and 2 interneurons implemented in the NEURON simulation environment. Modelling equations for the biophysical mechanisms used have been reported in [6,7]. All neuron models were biophysically detailed but morphologically simplified and were validated regarding their intrinsic, synaptic and connectivity properties (e.g. number of synapses, latencies etc). Our results show that the non-linear integration of synaptic inputs at the basal dendrites of pyramidal neurons, mediated by the

\footnotetext{
* Correspondence: papoutsi@imbb.forth.gr

'Institute of Molecular Biology and Biotechnology, Foundation for Research and Technology, Heraklion, Crete, 70013, Greece

Full list of author information is available at the end of the article
}

induction of NMDA-spikes, is imperative for the emergence of the persistent state in the microcircuit, but this necessity disappears when increasing the network size. Moreover dendritic versus somatic specific alterations of ionic currents (such as the R type VGCCs) differentially modulate persistent activity induction, substantiating the critical role of location specific effects of various neuromodulators. Finally, we find that several features of the network activity prior to the induction and/or termination of persistent firing contain predictive information of the upcoming state-transition(s), which is readily available to downstream neurons. These findings suggest that PFC microcircuits may serve as tunable and predictive modules of persistent activity and subsequently working memory.

\section{Author details}

${ }^{1}$ Institute of Molecular Biology and Biotechnology, Foundation for Research and Technology, Heraklion, Crete, 70013, Greece. ${ }^{2}$ Department of Biology, University of Crete, Heraklion, Crete, 71409, Greece.

Published: 8 July 2013

\section{References}

1. Ko H, Hofer SB, Pichler B, Buchanan Ka, Sjöström PJ, Mrsic-Flogel TD: Functional specificity of local synaptic connections in neocortical networks. Nature 2011, 473:87-91.

2. Song S, Sjöström PJ, Reigl M, Nelson S, Chklovskii DB: Highly nonrandom features of synaptic connectivity in local cortical circuits. PLoS biology 2005, 3:e68.

3. Litwin-Kumar A, Doiron B: Slow dynamics and high variability in balanced cortical networks with clustered connections. Nature neuroscience 2012, 15:1498-505.

4. Hira R, Ohkubo F, Ozawa K, Isomura Y, Kitamura K, Kano M, Kasai H, Matsuzaki M: Spatiotemporal Dynamics of Functional Clusters of Neurons in the Mouse Motor Cortex during a Voluntary Movement. The Journal of neuroscience: the official journal of the Society for Neuroscience 2013, 33:1377-1390.
(C) 2013 Papoutsi et al; licensee BioMed Central Ltd. This is an Open Access article distributed under the terms of the Creative Commons Attribution License (http://creativecommons.org/licenses/by/2.0), which permits unrestricted use, distribution, and reproduction in any medium, provided the original work is properly cited. 
5. Shu Y, Hasenstaub AR, McCormick DA: Turning on and off recurrent balanced cortical activity. Nature 2003, 423:288-293.

6. Sidiropoulou K, Poirazi P: Predictive Features of Persistent Activity Emergence in Regular Spiking and Intrinsic Bursting Model Neurons. PLoS Computational Biology 2012, 8:e1002489.

7. Durstewitz D, Gabriel T: Dynamical basis of irregular spiking in NMDAdriven prefrontal cortex neurons. Cerebral cortex 2007, 17:894-908.

doi:10.1186/1471-2202-14-S1-P319

Cite this article as: Papoutsi et al:: Dendritic nonlinearities enable PFC microcircuits to serve as predictive modules of persistent activity. BMC Neuroscience 2013 14(Suppl 1):P319.

Submit your next manuscript to BioMed Central and take full advantage of:

- Convenient online submission

- Thorough peer review

- No space constraints or color figure charges

- Immediate publication on acceptance

- Inclusion in PubMed, CAS, Scopus and Google Scholar

- Research which is freely available for redistribution

Submit your manuscript at www.biomedcentral.com/submit
Ciomed Central 